\title{
A Systematic Review on Vitex negundo (NIRPROMP formulations) for the Treatment of Acute Cough of Mild to Moderate Severity in Pediatric Patients
}

\author{
Daisy-Mae Alegado-Bagaoisan, ${ }^{1}$ Mary Christine R. Castro ${ }^{2}$ and Jaime M. Purificacion ${ }^{1}$ \\ ${ }^{1}$ Institute of Herbal Medicine, National Institutes of Health, University of the Philippines Manila, Philippines \\ ${ }^{2}$ Nutrition Center of the Philippines, Madrigal Business Park, Ayala Alabang, Philippines
}

\begin{abstract}
Objective. The aim of this systematic review was to evaluate the efficacy and safety of Vitex negundo (lagundi) for the treatment of acute cough of mild to moderate severity among pediatric patients.

Methods. A systematic review of randomized controlled trials (RCTs) comparing lagundi to placebo for acute cough of mild to moderate severity in children and adolescents aged two to twenty one years in ambulatory settings was performed. Authors of unpublished clinical trials with existing patent numbers were contacted and permission was obtained to access and include their studies in this review.
\end{abstract}

Results. Seven studies were included, with a total of 308 participants. Lagundi increased the peak exploratory flow rate (PEFR) at the end of therapy compared with placebo but this was not statistically significant $(p=0.36)$. The increase in PEFR was consistent with the results of the mechanistic isolated tissue studies that showed bronchodilating effect of lagundi. Studies using lagundi syrup showed decrease in the frequency of cough by $44-71 \%$.

Conclusion. Lagundi therapy in acute cough of mild to moderate severity among pediatric patients has a bronchodilating effect and decreases the frequency and duration of coughing, with no serious adverse effects.

Key Words: Vitex negundo, lagundi, cough

\section{INTRODUCTION}

Cough is the most common symptom in primary care in which patients seek medical consultation, and persistent cough among children is normally the reason for a child to be referred to a physician and pulmonologist. ${ }^{1}$ On the average, normal children cough 11 times per day when they are well and this increases in frequency and severity when there is presence of upper respiratory tract infections. ${ }^{2}$ Cough can either be acute or chronic. Acute cough is a recent onset of cough lasting less than 3 weeks while chronic cough last greater than 8 weeks. Cough can also either be specific or non-specific, recurrent, or post-viral. Specific cough is a cough in which there is a clearly identifiable cause. Nonspecific cough is a persistently dry cough with no other associated respiratory symptoms. The majority of cough cases is due to a non-serious etiology and may spontaneously resolve by itself. ${ }^{3}$ On the other hand, recurrent cough is a repeated cough (with episodes of $\geq 2 /$ year) not associated Corresponding author: Daisy-Mae O. Alegado-Bagaoisan, RPh Institute of Herbal Medicine National Institutes of Health University of the Philippines Manila 623 Pedro Gil St., Ermita, Manila 1000, Philippines Email: dabagaoisan@up.edu.ph with head colds lasting more than 7-14 days while post-viral cough is a cough that starts with an upper respiratory tract infection but the duration is greater than 3 weeks. ${ }^{4}$ 


\section{Description of the intervention}

Vitex negundo Linn Family Verbenaceae (lagundi) is a woody, erect, branched shrub 2-5 meters in height, and bears tri- or penta-foliate leaves, and with bluishpurple colored flowers. Lagundi is generally used for the treatment of coughs, asthma symptoms, and other respiratory problems. It has been recognized by the Philippine Department of Health as an effective clinically proven medicinal plant in the treatment of respiratory complaints like cough and asthma. ${ }^{5}$

An in-vivo study on the antitussive effects of an n-butanol fraction of Vitex negundo on sulphur-dioxideinduced cough performed in mice showed that the butanolic extracts of Vitex negundo demonstrated significant inhibition of cough reflex in a dose-dependent manner. The antitussive activity of a $250 \mathrm{mg} / \mathrm{kg}$ dose at 30 minutes was less than those of higher doses at all time points, while the highest inhibition of cough reflex was achieved at $1000 \mathrm{mg} / \mathrm{kg}$ dose of the extract at 60 minutes. $^{6}$

Isolation studies on the phytochemistry of Vitex negundo conducted by Dayrit (1987) showed the presence of several isolates identified as B-sitosterone from the hexane fraction, and casticin, chrysophenol D, luteolin, and alpha-hydroxybenzoic acid from the ethyl acetate fraction. ${ }^{7}$ A joint study with Kazuro Yamasaki of Hiroshima University School of Medicine, using cats' trachea, revealed that the inhibition of histamine release was mostly found in the ethyl acetate fraction.

An in-vitro test done by Tigno in 1993 on isolated compounds from Vitex negundo showed that the activities were found in the iridoid and flavonoid fractions of the plant extract. Specifically, the fractions that contain the iridoids agnuside, lagundinin, and 2'-parahydroxybenzoyl mussaenosidic acid, and the flavonoids casticin and chrysophenol D were found to have anti-inflammatory potential. The anti-inflammatory action of lagundi is partly explained by its ability to inhibit chemotaxis, phagocytosis, and complement activation, both via the alternative and classical pathway. ${ }^{8}$ Yunos et $\mathrm{al}^{9}$ and Jana et $\mathrm{al}^{10}$ established the anti-inflammatory property of Vitex negundo extracts in acute and subacute inflammation. Anti-inflammatory and pain suppressing activities of fresh leaves are attributed to prostaglandin synthesis inhibition, ${ }^{11}$ and to antihistamine, membrane stabilizing, and anti-oxidant activities. ${ }^{12}$

Patel et al in 2009 utilizing normotensive anesthetized rats showed that the lagundi extract stabilized mast cells showing inhibitory effects on immediate hypersensitivity reactions and exhibited anti-eosinophilic activity which was considered the underlying mechanism involved in the anti-asthmatic effect of Vitex negundo. ${ }^{13}$

Khan, Shah et al in 2015 explored the mechanism underlying the effectiveness of Vitex negundo in hyperactive respiratory disorders using crude extract of the leaves and found that Vitex negundo possesses a combination of papaverine-like phosphodiesterase inhibitors (PPE) and diltiazem-like $\mathrm{Ca}^{++}$entry blocking constituents which partly explains its bronchodilating effect. ${ }^{14}$

Plant extracts tend to exhibit numerous pharmacological actions with multiple mechanisms, which are activated by several different types of compounds. There is considerable ethnomedical and pharmacological evidence ${ }^{15,16}$ that Vitex negundo possesses analgesic and anti-inflammatory, ${ }^{17-22}$ antihistaminic, antibacterial, ${ }^{23-26}$ antioxidant, ${ }^{27}$ and bronchodilating ${ }^{28,29}$ potential.

\section{Why it is important to do this review}

Lagundi is extremely relevant in primary care because if proven efficacious it will justify the use of lagundi in children with mild to moderate cough by improving a child's quality of life such as better school performance and ability to play free from worries produced by difficult coughing.

A systematic review evaluating the efficacy and safety of lagundi for reducing cough symptoms of mild to moderate severity among pediatric patients would be useful. Most studies have small sample sizes and combining them in a systematic review would give more meaningful results.

\section{METHODS}

\section{Literature Search}

Electronic search was done in various search engines namely the Cochrane Central Register of Controlled Trials (CENTRAL) (The Cocbrane Library, 1950 to February 2016), PubMed (2004 to February 2016), MEDLINE (1950 to February 2016), HERDIN, Philippine Index Medicus and Google Scholar. We also searched the Philippine Herbs and Supplements Research Database (www.herbs.ph).

Manual search for relevant articles on lagundi as antitussive agent available at the Department of Pharmacology and Toxicology, College of Medicine, University of the Philippines Manila and at the University of the Philippines Manila Medical Library was done. The database of the Philippine National Library was also searched. We also searched databases of complementary and alternative medicine literature and clinical trial registries. Authors of unpublished clinical trials with existing patent numbers were contacted and permission was obtained to access and include their studies in this review. (Appendices I - IV)

\section{Eligibility Criteria}

We included randomized controlled trials among participants aged two to twenty-one years with acute cough of mild to moderate severity given Vitex negundo (NIRPROMP formulations). We excluded studies that included participants with a chronic cough lasting more than three weeks. Only randomized controlled trials (RCTs) comparing Vitex negundo with placebo were included in this review. Studies comparing Vitex negundo to other pharmaceutical preparations for cough or asthma were excluded. 


\section{Types of outcome measures}

\section{Primary outcomes}

1. Improvement in PEFR function.

2. Reduction in frequency of cough

\section{Secondary outcomes}

1. Difficulty of breathing

2. Difficulty of expectoration

3. Change in the character of phlegm

4. Change in the color of phlegm

\section{Selection of studies}

The review authors merged and eliminated duplicates from the retrieved records identified through electronic database search and other sources. Two authors (DAB, JMP) independently extracted and entered data into Review Manager 5.3 (Revman 2013). A third author (MCC) resolved disagreements by consensus. (Figure 1)

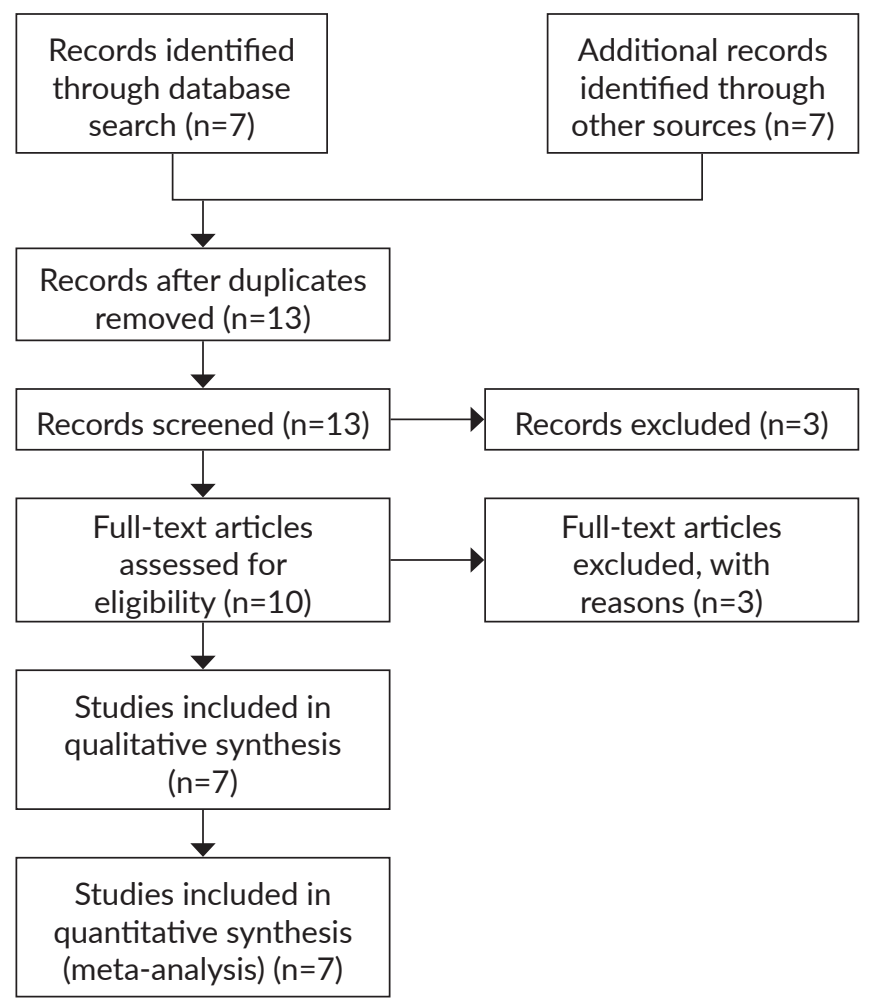

Figure 1. Selection of Studies Flow Diagram.

\section{Risk of bias in included studies}

Two authors (DAB, JMP) determined the risk of bias for the included studies by assessing random sequence generation, allocation concealment, blinding, selective reporting, and other sources of bias, and recorded the assessment in the 'Risk of bias' tables in Review Manager 5.3 (Revman 2013). We ranked the studies as low risk, unclear risk, and high risk of bias.

\section{Measures of treatment effect}

Five studies contributed data for the analysis of the reduction of cough (207 participants). For the peak exploratory flow rate (PEFR) improvement outcome, four studies (146 participants) contributed data. Mean difference and standard deviation were used for continuous outcomes.

\section{Dealing with missing data}

We contacted the authors of the unpublished clinical trials for clarifications on the missing data. Data for the reduction of the frequency of cough in the included studies were collapsed into two groups to standardize and create a uniform category on all included studies. Missing data were handled to predict and determine the impact of worst case and best case scenarios.

\section{Assessment of heterogeneity}

Included studies were first assessed for clinical heterogeneity by comparing the participants (age range, inclusion criteria), intervention (preparation and dosage), and outcomes (measurement, reporting). A meta-analysis using the fixed effects model was conducted for studies that reported similar methods of measuring outcomes. Statistical heterogeneity of the studies was conducted during the meta-analysis using the Chi-square test for heterogeneity at a $5 \%$ level of significance. The $\mathrm{I}^{2}$ statistic was used to measure impact of statistical heterogeneity.

\section{RESULTS}

\section{Description of studies}

\section{Included studies}

All the seven included studies were randomized, doubleblind clinical trials comparing efficacy of Vitex negundo L. to placebo for acute cough in patients aged 2 to 21 years old in ambulatory settings in the Philippines. The total number of subjects enrolled in the seven studies was 308 . Five of the studies included patients 17 years and below, while two studies included patients up to 21 years of age.

Six of the studies utilized Vitex negundo syrup while one study used Vitex negundo tablets. Among the six studies that used the syrup preparation, four studies used $45 \mathrm{mg} / \mathrm{kg} /$ day in 3 divided doses, one study used $30 \mathrm{mg} /$ $\mathrm{kg} / \mathrm{day}$ and one study explored both a $15 \mathrm{mg} / \mathrm{kg} / \mathrm{day}$ and $30-\mathrm{mg} / \mathrm{kg} / \mathrm{day}$ dose. The single study that provided Vitex negundo in tablet form used $300 \mathrm{mg}$ tablets $3 \mathrm{x}$ a day for children less than 10 years of age and $600 \mathrm{mg}$ tablets $3 \mathrm{x}$ a day for children 10 years old and above. In all the studies, placebo preparations that were similar to the intervention in form and concentration were given.

\section{Excluded studies}

Three studies were excluded namely 1) Chu in 1988 because the study evaluated the effects of lagundi tablet 


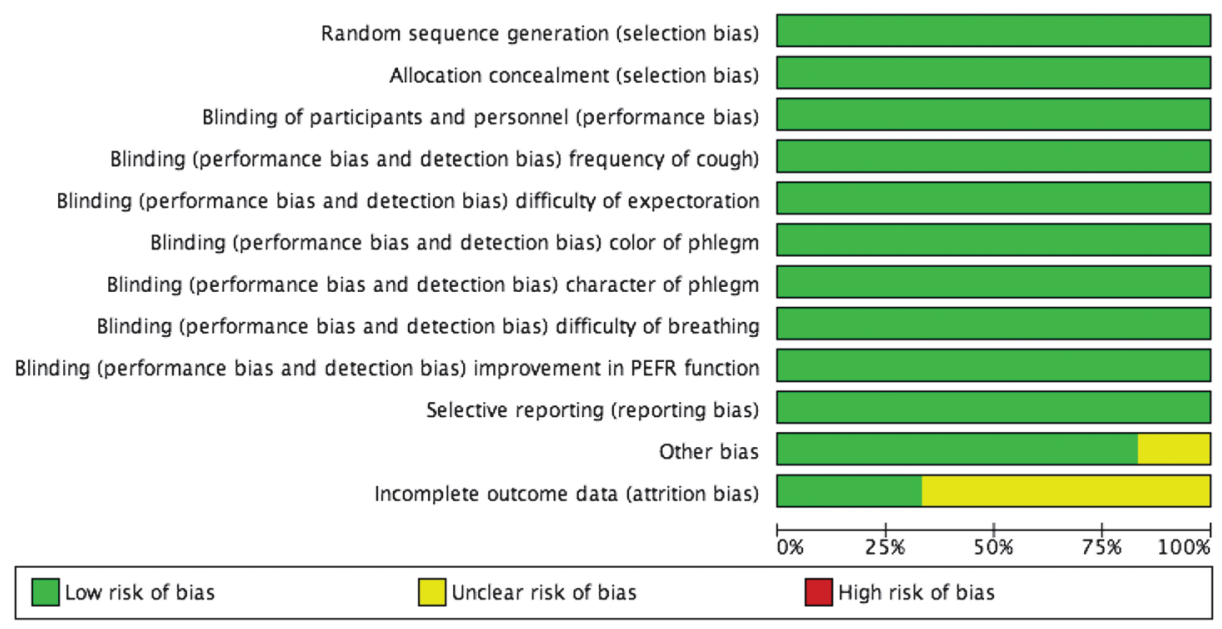

Figure 2. Risk of bias graph about risk of bias item presented as percentages across all included studies.

vs theophylline in bronchial asthma; 2) Dyseng in 1996 because the study evaluated the effect of lagundi tablet vs placebo for chronic cough in former smokers and 3) Lagundi Technology Transfer Document (TTD) Phase I (1993) of the National Integrated Research Program on Medicinal Plants (NIRPROMP) because this is a single blind randomized control trial between lagundi syrup vs placebo and bromhexine.

\section{Risk of bias in included studies}

Most RCTs were evaluated to be of good quality with a low risk of selection bias, performance and detection bias. Four studies presented incomplete outcome data as participants dropped out of the study. (Figure 2)

\section{Effects of interventions}

\section{Data and Analyses (Appendix V)}

\section{Descriptive Analysis of Included Studies}

In this systematic review, except for the study done by Maramba et al 1989 where randomization sequence was done by a statistician not affiliated with the study, all the other six studies used a table of random numbers for randomization and this was verified with the authors of the studies. In the Maramba et al 1989 study, lagundi tablet was given at $300 \mathrm{mg} /$ tablet $3 \mathrm{x}$ a day for children less than 10 years old and $600 \mathrm{mg} /$ tablet $3 \mathrm{x}$ a day for children 10 years old and above. Patients in the placebo arm received matching tablets on the same regimen. Two follow-up visits were done at 3-day intervals. Lagundi syrup was given in the other six studies. In the Phase II studies done in 1993, lagundi syrup prepared as $300 \mathrm{mg} / 5 \mathrm{~mL}$ was given at a dose of $30 \mathrm{mg} / \mathrm{kg} /$ day or $10 \mathrm{mg} / \mathrm{kg} /$ dose administered $3 \mathrm{x}$ a day. In another Phase II study done in July-December 1993, lagundi syrup was given in two dose levels: low dose $(15 \mathrm{mg} /$ $\mathrm{kg} /$ day) and high dose (30 mg/kg/day) in 3 divided doses. However, in the Phase II trial done in 1994, lagundi syrup was given in one dose only at $15 \mathrm{mg} / \mathrm{kg} /$ dose $(0.25 \mathrm{ml} / \mathrm{kg} /$ dose). In the Phase III clinical trial done from January to December 1996, September to December 1997 and January to December 1998, lagundi syrup was given at a dose of $15 \mathrm{mg} / \mathrm{kg} /$ dose given $3 \mathrm{x}$ daily $(45 \mathrm{mg} / \mathrm{kg} /$ day).

Clinical parameters (frequency of cough and difficulty of expectoration) were obtained in 4 studies namely, (a.) Phase II July-December 1993, (b.) Phase III 1996, (c.) Phase III 1997 and (d.) Phase III 1998. Difficulty of breathing as clinical parameter was obtained in all the Phase III studies (Phase III 1996, Phase III 1997 and Phase III 1998). Frequency of cough, difficulty of expectoration, color and character of phlegm, and difficulty of breathing were not obtained in 3 studies (Maramba et al 1989, Phase II 1993 and Phase II 1994). Efficacy evaluation was done using a visual cough severity and cough relief scales and by the physician using objective parameters and global assessment at the end of the patient's follow-up.

Peak Expiratory Flow Rate (PEFR) as an objective clinical parameter was obtained in all patients of 6 studies (Phase II 1993, Phase II July-December 1993, Phase II 1994, and all Phase III studies namely (a.) 1996, (b.) 1997 and (c.) 1998) except in the study by Maramba et al in 1989 wherein PEFR was done only in cooperative participants. All outcomes were adequately reported in all the 7 studies. All patients who dropped out from the study were not included in the final analysis. A total of 37 patients were dropped from the study; 1 participant was lost to follow-up and 2 developed acute tonsillitis (Maramba et al 1989); 14 subjects dropped out and 1 showed no medical improvement requiring standard medical therapy (Phase II 1993); 19 subjects dropped out from (Phase II July-December 1993); 1 participant from the placebo group dropped out (Phase III 1996). 
There was some heterogeneity among the studies in terms of outcome measurement, thus data abstraction was not done due to heterogeneity in outcome reporting. While all seven studies measured peak expiratory flow rates at baseline and follow-up visits, one study was only able to measure PEFR in cooperative patients. Vitex negundo increased mean PEFR of subjects at the end of therapy compared to placebo (MD 10.22, 95\% CI -11.58 to 32.02; participants $=146$; studies $=6 ; \mathrm{I}^{2}=0 \%$ ), but this effect was not statistically significant ( $p$-value $=0.36$ ). The four studies that reported mean PEFR at the end of therapy showed low heterogeneity $\left(\mathrm{I}^{2}=0 \%\right)$ (Analysis 1 ). Although the result was not statistically significant, the increase in PEFR values effected by Vitex negundo treatment reinforced the results of clinical and experimental studies tending to show bronchodilating property of lagundi.

Frequency of cough was not measured in a standard way. Visual analog scales (VAS) were used to rate frequency, cough severity and cough relief in 3 of the 7 studies. One study used a 4 to 5-point scale. Furthermore, outcomes were not stratified according to age group. When all missing data were imputed to have good outcomes, Vitex negundo significantly decreased cough frequency by $60 \%$ compared to placebo. (OR 0.41, 95\% CI 0.11 to 1.47; participants=207; studies $=5 ; \mathrm{I}^{2}=41 \%$ ) ( $\mathrm{p}$-value=0.17) (Analysis 2). However, when all missing data were imputed to have poor outcomes, the effect size was smaller (33\%) and not statistically significant. (OR 0.67, 95\% CI 0.35 to 1.30; participants=207; studies $\left.=5 ; \mathrm{I}^{2}=0 \%\right)(\mathrm{p}$-value $=0.24)$ (Analysis 3$)$. We expect the true value of the odds ratio of cough reduction comparing Vitex negundo to placebo in this sample to be between 0.41 and 0.67. It is significant to note that 2 of the studies (Phase III 1997 and 1998) had missing cough data at the end of therapy for more than $25 \%$ of the treatment group. These studies were still included in the analysis. For the reduction of cough outcome, low heterogeneity $(\mathrm{I} 2=0 \%)$ was also seen among the five studies included for the 'worst case scenario' (all missing data imputed with poor outcomes). When the missing data was imputed with good outcomes ('best case scenario'), there was moderate heterogeneity (I2=41\%).

When we limited the analysis to $V$. negundo syrup and excluded the only study that used the tablet preparation, $V$. negundo reduced cough frequency by at least 44\% (not statistically significant, $\mathrm{p}=0.11$ ) (Analysis 4 ) to at most $71 \%$ (statistically significant, $\mathrm{p}=0.006$ ) (Analysis 5).

\section{DISCUSSION}

There was a consistent increase in PEFR values effected by lagundi treatment that reinforces the results of clinical and experimental studies tending to show bronchodilating property of lagundi. Bronchodilation may be a favorable characteristic of a cough preparation since some of these acute cough have associated bothersome bronchospasm.

There was a statistically significant $(\mathrm{p}=0.006)$ reduction in cough frequency when studies using only $V$. negundo syrup were analyzed. Medical studies have shown that drugs in liquid form exhibit a higher rate of bioavailability compared to the same drug of equivalent dose formulated in tablets or capsule because of the large surface area and high dissolution rate of the liquid preparation. Liquid preparations also have faster absorption rate, higher optimization rate and is more easily digestible. ${ }^{30}$ The body does not need to break down a liquid formulation thereby allowing more of the $V$. negundo syrup preparation to be absorbed into the system. The liquid extracts take 1-4 minutes to assimilate in contrast to tablet or capsule which take 20-30 minutes just to break down, before the body can even start to assimilate them. ${ }^{31}$

The frequency of coughing was significantly decreased by the first follow-up in the lagundi group. However, patients who received placebo also had significant improvement but only by the second follow-up, which suggests that, the usual course of non-bacterial respiratory tract infection (ex. viral etiology) among the study population would last for 6 days in $94-100 \%$ of patients as evaluated by the patients themselves and the physician. For younger children, the administration of lagundi was no better than the placebo with regard to the clinical parameters used because of the actual difficulty in assessing clinical improvement because of their inability to express by themselves their clinical symptoms.

There was no statistically significant difference noted in response to therapy based on subjective parameters, but there were more patients with acute mild to moderate cough treated with lagundi who improved. At the same time, more patients treated with lagundi showed improvement in the color and character of their phlegm.

\section{Potential biases in the review process}

One of the review authors participated as co-investigator in four of the seven included studies. The four studies are (a.) NIRPROMP TTD Phase II (1994), (b.) NIRPROMP TTD Phase III (1996, 1997 and 1998).

\section{Agreements and disagreements with other studies or reviews}

There were no other systematic reviews on lagundi for the treatment of acute cough of mild to moderate severity that has been published or searched by the authors.

\section{CONCLUSIONS}

Lagundi therapy in acute cough of mild to moderate severity among pediatric patients has a bronchodilating effect and decreases the frequency and duration of coughing, with no serious adverse effects.

\section{Limitation of the study}

The number of participants was small in the included clinical studies. The age group of the pediatric patients included in the study should be the same across all the clinical studies done. 


\section{Recommendations}

A large scale clinical trial should be conducted that utilize standardized objective and subjective measures. Objective measures of cough frequency such as automated cough frequency monitors and software ${ }^{32}$ are now already available. For patient important outcomes, the Leicester Cough Questionnaire (LCQ) or Cough-specific Quality of life questionnaire $(\mathrm{CQ1Q})^{33-35}$ which has been validated for use in acute cough can be employed.

\section{Statement of Authorship}

All authors participated in data collection and analysis, and approved the final version submitted.

\section{Author Disclosure}

Dr. Purificacion was involved in 4 studies which were included in the analysis.

\section{Funding Source}

This paper was funded by the authors.

\section{REFERENCES}

1. Chang AB. Chronic non-specific cough in children. Paediatr Child Health. 2008;18(7):333-9.

2. Munyard P, Bush A. How much coughing is normal? Arch Dis Child. 1996; 74(6):531-4.

3. Shields MD, Bush A, Everard ML, McKenzie S, Primhak R. British Thoracic Society Cough Guideline Group BTS Guidelines: Recommendations for the assessment and management of cough in children. Thorax. 2008; 63(Suppl 3):1-15.

4. Sherrill DL, Guerra S, Minervini MC, Wright AL, Martinez FD. The relation of rhinitis to recurrent cough and wheezing: A longitudinal study. Respir Med. 2005; 99(11):1377-85.

5. Dayrit FM, Macahig RS. Encyclopedia of common Medicinal Plants of the Philippines Volume 1. Philippine Institute of Traditional and Alternative Health Care (PITAHC). 2014; pp. 350-364.

6. Haq RU, Shah AU, Khan AU, Ullah Z, Khan HU, Khan RA, et al. Antitussive and toxicological evaluation of Vitex negundo. Nat Prod Res. 2012; 26(5):484-8.

7. Dayrit FM. Phytochemistry of Vitex negundo L.: Isolation and Identification of the pharmacologically active constituents. PCHRD-PIPAC 8302Md.: Mid-Year Progress Report. 1987.

8. Tiglao TT, Francisco AD. The comparative effects of purified fraction of Vitex negundo, L (lagundi) and crude extracts of Cassia alata L. (akapulko) and Artemesia vulgaris L. (damong-maria) on inflammatory processes in vitro. NRCP Research Journal. 1993; 3(2):349-54.

9. Yunos NM, Mat Ali R, Kean OB, Abas R. Cytotoxicity Evaluations on Vitex negundo anti-inflammatory extracts. Malaysian Journal of Science. 2005; 24(1):213-7.

10. Utpalendu J, Chattopadhyay RN, Badri PS. Preliminary Studies on Anti-inflammatory activity of Zingiber officinale Rosc, Vitex negundo Linn and Tinospora cordifolia (Wullid) Miers in albino rats. Indian J Pharmacol. 1999; 31(3):232-3.

11. Telang RS, Chatterjee S, Varshneya C. Studies on analgesic and antiinflammatory activities of Vitex negundo Linn. Indian J Pharmacol. 1999; 31(5):363-6.

12. Dharmasiri MG, Jayakody JR, Galhena G, Liyanage SS, Ratnasooriya WD. Anti-inflammatory and analgesic activities of mature fresh leaves of Vitex negundo. J Ethnopharmacol. 2003; 87(2-3):199-206.

13. Khan M, Shah AJ, Gilani AH. Insight into the bronchodilator activity of Vitex negundo. Pharm Biol. 2015; 53(3):340-4.
14. Patel JI, Shah SK, Deshpasde SS, Shah GB. Evaluation of antiasthmatic activity of leaves of Vitex negundo. Asian J Pharm Clin Res. 2009; 2(1):81-6.

15. Ladda PL, Magdum CS. et al. Vitex negundo Linn: Ethnobotany, Phytochemistry and Pharmacology- A review. Int J Adv Pharm Biol Chem. 2012; 1(1):111-20.

16. Tandon VR. Medicinal uses and biological activities of Vitex negundo. Nat Prod Rad. 2005; 4(3):162-5.

17. Chattopadhyay P, Hazarika S, Dhiman S, Upadhyay A, Pandey A, Karmakar S, et al. Vitex negundo inhibits cyclooxygenase-2 inflammatory cytokine-mediated inflammation on carrageenaninduced rat hind paw edema. Pharmacognosy Research. 2012; 4(3):134-7.

18. Dharmasiri MG, Jayakody JR, Galhena G, Liyanage SS, Ratnasooriya WD. Anti-inflammatory and analgesic activities of mature fresh leaves of Vitex negundo. J Ethnopharmacol. 2003; 87(2-3):199-206.

19. Gupta RK, Tandon VR. Antinociceptive activity of Vitex-negundo Linn leaf extract. Indian J Physiol Pharmacol. 2005; 49(2):163-70.

20. Kulkarni RR, Virkar AD, Priscilla D'mello. Antioxidant and antiinflammatory activity of Vitex negundo. Indian J Pharm Sci. 2008; 70(6):838-40.

21. Tandon VR, Gupta RK. Vitex negundo Linn (VN) leaf extract as an adjuvant therapy to standard anti-inflammatory drugs. Indian J Med Res. 2006; 124(4):447-50.

22. Vinuchakkaravarthy T, Kumaravel KP, Ravichandran S, Velmurugan D. Active compound from the leaves of Vitex negundo L. shows anti-inflammatory activity with evidence of inhibition for secretory Phospholipase A (2) through molecular docking. Bioinformation. 2011; 7(4):199-206.

23. Devi PR, Kokilavani R, Poogotha SG. Antimicrobial activity of the various leaf extracts of Vitex negundo Linn. Anc Sci Life. 2008; 27(4):22-7.

24. Kannathasan K, Senthilkumar A, Venkatesalu V. In vitro antibacterial potential of some Vitex species against human pathogenic bacteria. Asian Pac J Trop Med. 2011; 4(8):645-8.

25. Nagarsekar KS, Nagarsenker MS, Kulkarni SR. Evaluation of composition and antimicrobial activity of supercritical fluid extract of leaves of Vitex negundo. Indian J Pharm Sci. 2010; 72(5):641-3.

26. Kamruzzaman M, Bari SM, Faruque SM. In vitro and in vivo bactericidal activity of vitex negundo leaf extract against diverse multidrug resistant enteric bacterial pathogens. Asian Pac J Trop Med. 2013; 6(5):352-9.

27. Praveen Kumar P, Kumaravel S, Lalitha C. Screening of anti-oxidant activity, total phenolics and GC-MS study of Vitex negundo. Afr J Biochem Res. 2010; 4(7):191-5.

28. Khan M, Shah AJ, Gilani AH. Insight into the bronchodilator activity of Vitex negundo. Pharm Biol. 2015; 53(3):340-4.

29. Patel J, Shah S, Deshpande S, Shah G. Evaluation of the antiasthmatic activity of leaves of Vitex negundo. Asian J Pharm Clin Res. 2009; 2(1):81-6.

30. Medicare Europe, Liquid vs Pills [Internet]. 2018 [cited 2019 Jan]. Available from https://medicare-europe.co.uk/science-clinical-data/ liquids-vs-pills.html

31. Pain Assist, Opioids/Rx Treatment for Various Medical Conditions [Internet]. 2018 [cited 2019 Jan]. Available from https://www. epainassist.com $>$ Opioids/Rx Treatment $>$ Medications

32. Pavesi L, Subburaj S, Porter-Shaw K. Application and validation of a computerized cough acquisition system for objective monitoring of acute cough: a meta-analysis. Chest. 2001; 120(4):1121-8.

33. Spinou A, Birring SS. An update on measurement and monitoring of cough: what are the important study endpoints? J Thorac Dis. 2014; 6(Suppl 7):S728-34.

34. Sunger K, Powley W, Kelsall A, Sumner H, Murdoch R, Smith JA. Objective measurement of cough in otherwise healthy volunteers with acute cough. Eur Respir J. 2013; 41(2):277-84.

35. Morice AH, Fontana GA, Belvisi MG, Birring SS, Chung KF, Dicpinigaitis PV, et al. ERS guidelines on the assessment of cough. Eur Respir J. 2007; 29(6):1256-76. 


\section{APPENDICES}

Appendix I. PUBMED search strategy

1. Vitex negundo (160)

2. Cough (43200)

3. Lagundi (2)

4. 1 and 2 (1)

5. 2 and $3(0)$

6. 1 and 2 and $3(0)$

Appendix II. Philippine Index Medicus search strategy

1. Vitex negundo (0)

2. Cough (14)

3. Lagundi (0)

4. 1 and $2(0)$

5. 2 and $3(0)$

6. 1 and 2 and $3(0)$
Appendix III. CENTRAL search strategy

1. Vitex negundo (4)

2. Cough (216)

3. Lagundi (2)

4. 1 and 2 (1)

5. 2 and 3 (1)

6. 1 and 2 and 3 (1)

Appendix V. Data and Analyses

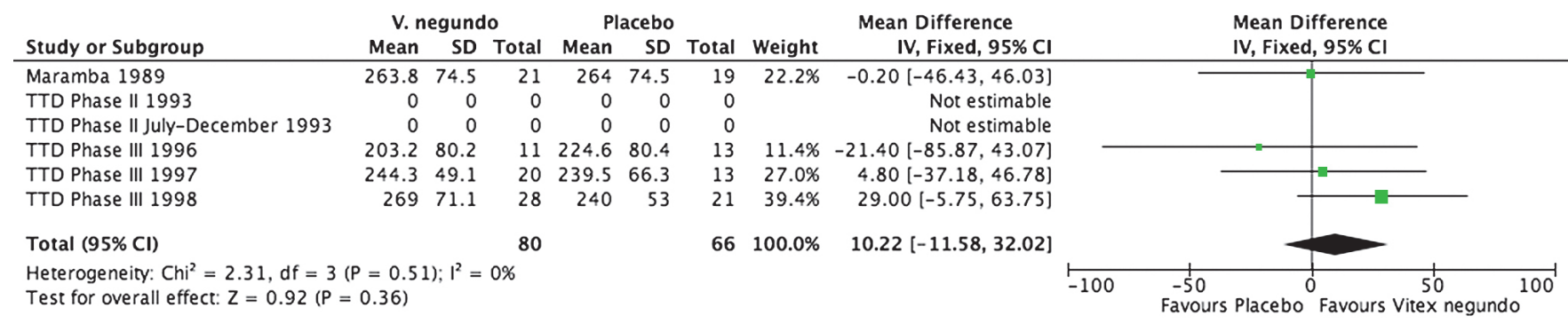

Analysis 1. Forest Plot of Comparison of Included Studies for PEFR at End of Therapy.

Appendix IV. HERDIN search strategy

1. Vitex negundo (24)

2. Cough (194)

3. Lagundi (27)

4. 1 and 2 (7)

5. 2 and $3(7)$

6. 1 and 2 and $3(6)$

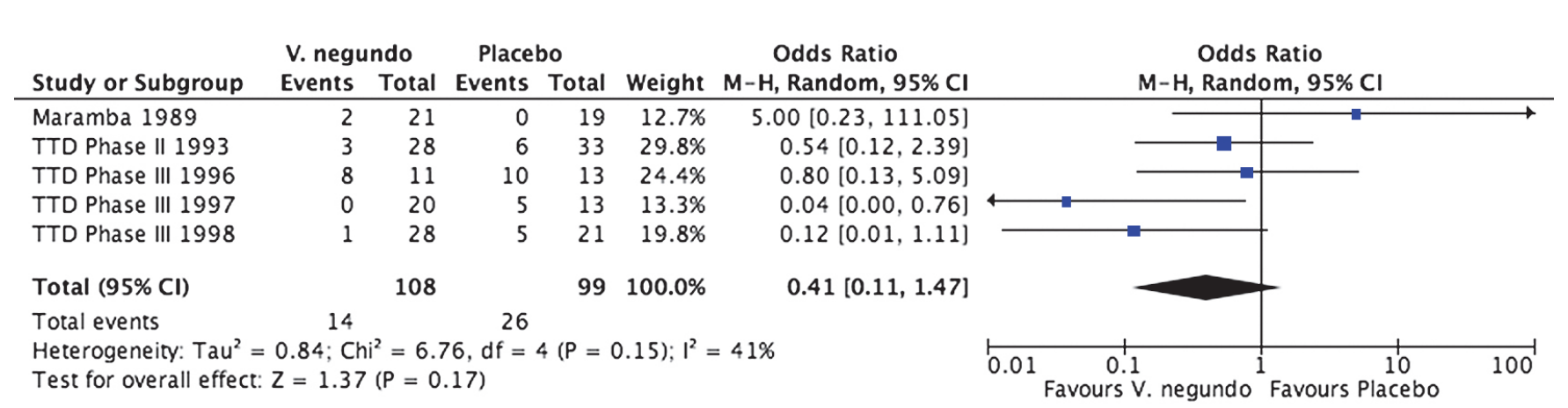

Analysis 2. Forest Plot of Comparison of Included Studies for Reduction in frequency of cough, best case (FE model).

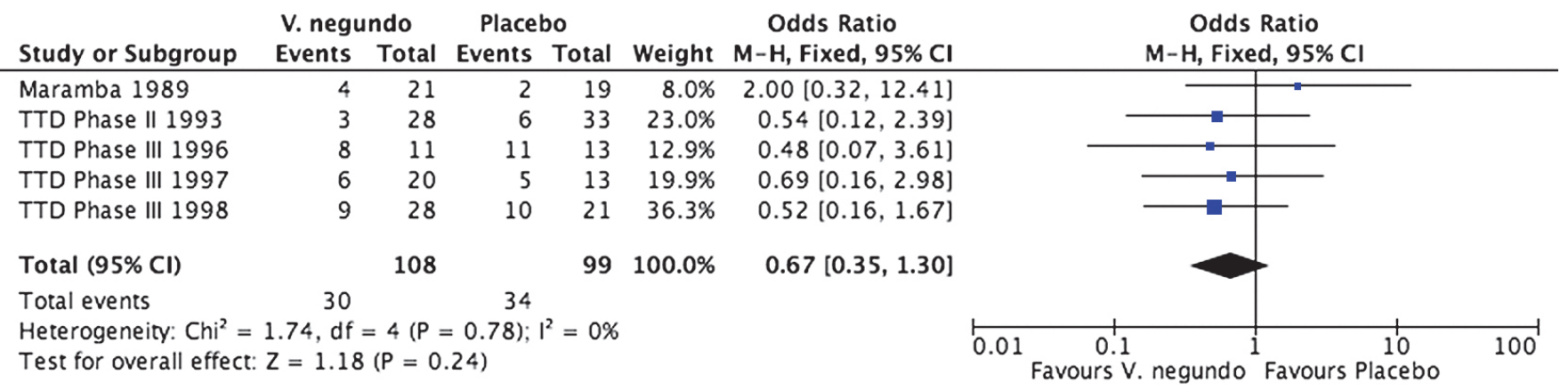

Analysis 3. Forest Plot of Comparison of Included Studies for Reduction in frequency of cough, worst case. 


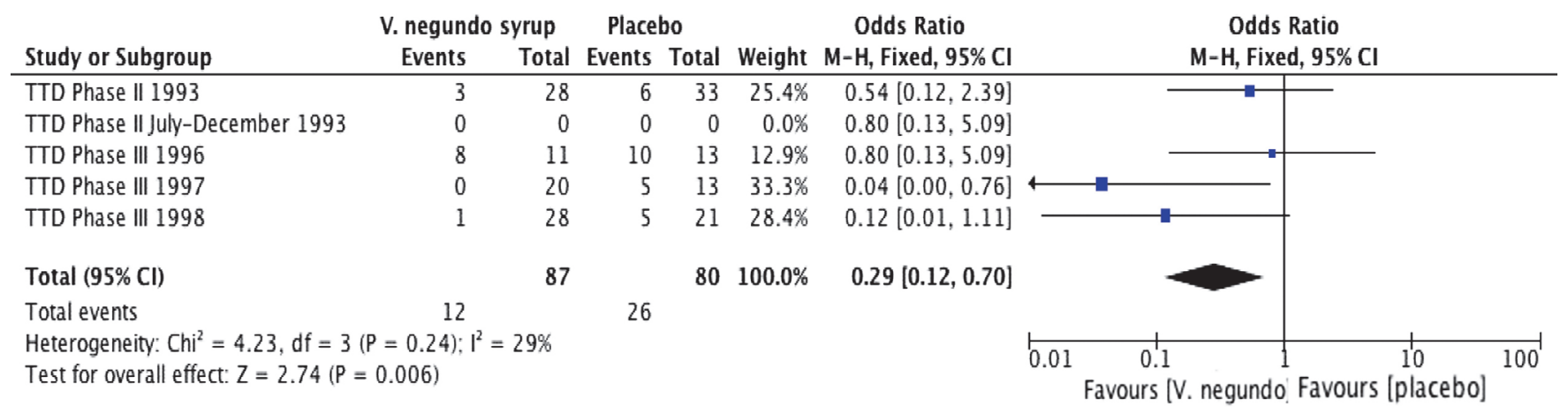

Analysis 4. Forest Plot of Comparison of Included Studies, V. negundo syrup only for Reduction in frequency of cough, best case.

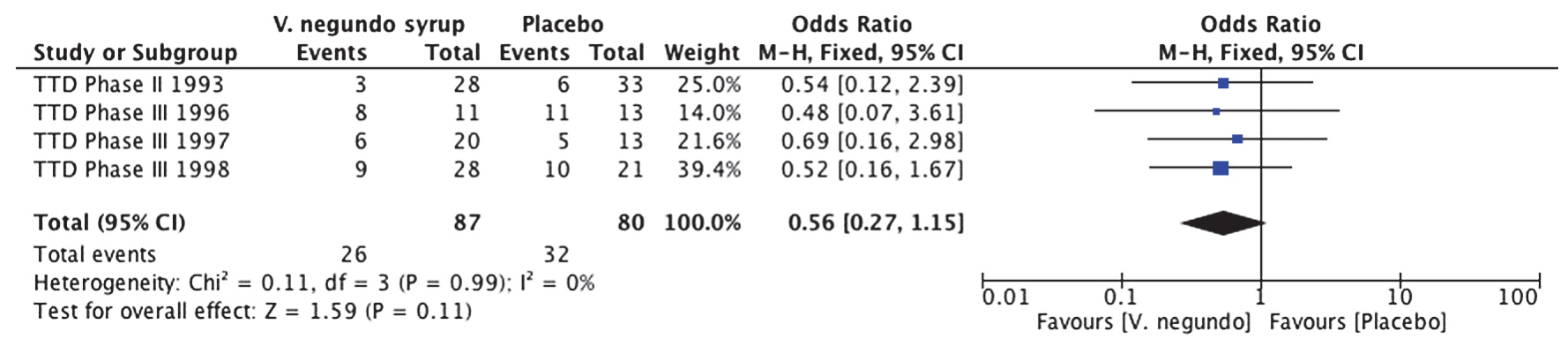

Analysis 5. Forest Plot of Comparison of Included Studies, V. negundo syrup only for Reduction in frequency of cough, worst case. 